\title{
IS SOCIAL RESILIENCE AN ECONOMIC STRUCTURE ISSUE OR JUST THE ABILITY OF COMMUNITIES TO COPE WITH EXTERNAL STRESS ?
}

\author{
Paul-Răzvan ȘERBAN*, Cristian TĂLÂNGĂ ${ }^{* *}$ \\ * University of Bucharest, Vasile Goldis Western University of Arad, Romania \\ ** University of Bucharest, Romania
}

\begin{abstract}
The paper analyzes social resilience at county level in Romania, in the context of the recent global financial and economic crisis. Generally, social resilience is seen as the ability of communities to cope with external stress such as changes in the economic environment. This study emphasizes the vulnerabilities of economies where communities live in, namely the particularities of economic environment where human communities evolve and co-evolve by resilience emergence. Thus, the link between the social and the economic component requires a special attention, initially external shock being experienced by the economic structure, which, to respond to sudden changes, dissipates shock to the other components of the social-economic system, namely the social component. The close relationship between the economic and the social components causes economies deepening into crisis by triggering a circular causality process. The population's decision to change residence interrupts this process, leading to social resilience.
\end{abstract}

Key Words: social resilience, labor market, population movement, Romania

\section{Introduction}

In social-ecological systems, adaptive capacity refers to the ability of people to cope with the change in their environment, by observing, learning and altering their interactions (Folke 2006). Resilience is able to provide shock absorption capacity, while maintaining the function. When change occurs, resilience offers components for (system) renewal and reorganization (Gunderson 2002, Holling and Gunderson 2002, Barthel et al. 2014).

Luthar and Cushing (1999) and Gartstein et al. (2014) argue that resilience cannot be directly measured, but only inferred, based on two concepts that compose it: the risk (or adversity) and successfully adaptation (or competence). Thus, differences in social resilience may occur either because of different risks to which the population was subjected, whether as a result of various population competences (skills, the ability to see opportunities in the labor market).

Vulnerability is the other side of resilience, so that when the social system loses resilience, it becomes vulnerable to change that initially was able to absorb (Kasperson and Berberian 2011). As Perman et al. (2003) observed, the (negative) feedback loops lower the level of resilience. Some economic activity seemed to reduce resilience so that the magnitude of disturbance the system is subject to, without producing a parametric change, decreases. So, the risk for population of losing their jobs (for demand and supply matching on the labor market, see Mocanu 2011) is increased in regional economies that undergo significant vulnerabilities.

As resilience decreases, the social-economic system becomes more vulnerable, so that smaller shocks lead to achieving the critical threshold beyond which the system's evolution is changing. Thus, the distribution of economic and social variables becomes sharply 
uncorrelated. That had an impact on the upward trend of economic development.

Starting from the definition of the resilience provided by Holling et al. (1995) - the system's ability to absorb disturbances or the size of disturbance that can be absorbed before the system changes its structure by altering its variables or the processes that control system behavior - we consider that social resilience is just a type of it. When referring to the socialeconomic system, we consider the behavior of the employed population who, faced with changes in the economic component, avoids exit from the labor market by hiring in another economic activity and by changing the place of residence. However, all these should be viewed through the prism of sustainable development broadly, Common and Perrings (1992) argue that there is a close relationship between resilience and sustainable development. The components are linked together, as Gual and Norgaard (2010) claimed synergistic linkages and co-evolutionary connections between the ecological and the social component. We appreciate that the social and the economic component are linked together, the internal changes of one bringing changes in the other.

Among social-economic indicators, unemployment is the interface between the economic and the social component, economic decisions in reducing the size of businesses directly reflecting on population behavior. Therefore, we take unemployment as a landmark in the analysis of resilience because it greatly influences population decisions in changing the place of residence, thus affecting the stability of the population. Even if mobility is seen as one of the important indicators of social resilience, Adger (2000) notes that resilience conclusions can be drawn only by analyzing the presence or absence of migrants in a given area or community. The movement of the population may be an important evidence of instability or, conversely evidence of increased stability of the population, as it depends on the type of migration (Adger 2000). Economists belonging to the neoclassical stream model the migration decision as an individual decision for adaptation and for household risk dispersion (Ruitenbeek 1996, Adger 2000).

At the same time, Ruttan (1998) emphasizes that contemporary economic theories and policies, based on the premise that economic growth depends on social infrastructure, are continuously expanding. In addition, economic growth is assumed to depend on positive externalities capture from investment in human capital (Hayami and Ruttan 1985, Stern 1996). Employees in the formal sector are considered, by Machlis et al. (1990), elements of resilience at community level.

When we look at the effects produced by the recent economic and financial crisis on regional economies, we look at the number of the unemployed. Although, initially we had in mind differences which may exist in respect of employment in different economic activities, the conclusions we draw are often limited to the adaptation of the population. So, we lose sight of risk, namely of economic activities being differently exposed to the economic crisis. Furthermore, redundancies in various economic activities offer different possibilities for further employment, depending on the skills gained and the similarities between the economic activity of origin of the unemployed and the economic activities where jobs are available. Job exchange aims to facilitate the job/worker matching, reducing input flows in unemployment, negative job attitude, and low job satisfaction (Mocanu 2011). In conclusion, the study of social resilience should not be limited to assessing the opportunities which determine the redundant population to change its place of residence when finding a job in another locality. The study should include information on the vulnerabilities of the economy, in this case, on how some regional economies were exposed to the economic crisis.

\section{Materials and methods}

We aim to investigate the correlations between the number of the unemployed resulted from 
the economic crisis, on the one hand, and the number of the existing employees by economic activity when the crisis occurs, also the changes in the number of employees in different economic activities during the crisis and, on the other hand, the evolution of the change of residence, in order to have a complete picture of the relations between the social and the economic component in the social-economic system. The economic activities taken into consideration are: agriculture, industry, construction and commerce. The analyzed period is 2009-2011 and the level of data aggregation is NUTS III in Romania. Data source is the National Institute of Statistics. The method used to analyze the geographical data is the Hierarchical Ascending Classification (HAC). By this method we obtain regional typologies of social risk to which the population was subjected and the population's ability to avoid becoming unemployed once the economic crisis has been triggered. HAC allows a precise hierarchy over a vast set of data after a certain data aggregation strategy: minimum link, minimum diameter, average distance, and variance. This helps the rapid creation of nested partitions in a dataset (Bruynooghe 1977).

\section{Results and discussion}

We intend to analyze resilience from the following perspective: the global economic crisis meant a disturbing factor for the Romanian economic system, and it imposed special measures to be taken by the economic agents and among these measures layoffs were most important. In this way, disturbance was dissipated into the system, from the economic component to the social component (the population was forced to act in order to maintain itself on the labor market). The question is whether the economic component of the resilience that emerged means equally social resilience or, on the contrary, we are dealing with two processes, and even if they are dependent on each other, the emergence of one is not conditioned by the occurrence of the other.

The analysis of social resilience in the Romanian social-economic system is a two-step approach:

- the influence of external shock (economic crisis) on the economic component;

- the propagation of changes from the economic to the social component.

We begin by analyzing the influence of the economic crisis on economic activities in Romania at county level. To achieve this, a HAC was run using data representing: the number of the employees by economic activities in 2009; the evolution of the number of employees in those economic activities in 2009-2011; the number of the unemployed people in 2009; and the evolution of the unemployed in the above mentioned period. Also, a typology of counties using the number of the occupied people by economic activities instead of the number of employees by economic activities for the same period was made. In this way we want to compare the results, knowing that agriculture, an economic activity which plays an important role in social resilience during the economic crisis, registers significant differences between the number of the employees and the number of the occupied people.

Generally, a process of redistribution in the territory of the occupied people and of the unemployed can be observed. This is very evident in the case of classes comprising the largest number of counties (classes 2, 3, 4,5). Here, the evolution trend over 2009-2011 is opposed to the territorial stock spreading in 2009. More specifically, if the number of the occupied people by different economic activities was above the national average, the evolution was negative and when the number of the occupied people was below the national average the evolution was above the national average. A process of circular causality whereby territorial spreading is correlated with evolution was observed in class 6 for agriculture and industry while a process of conversion from agriculture to industry can be seen in class 1 (Fig. 1). 

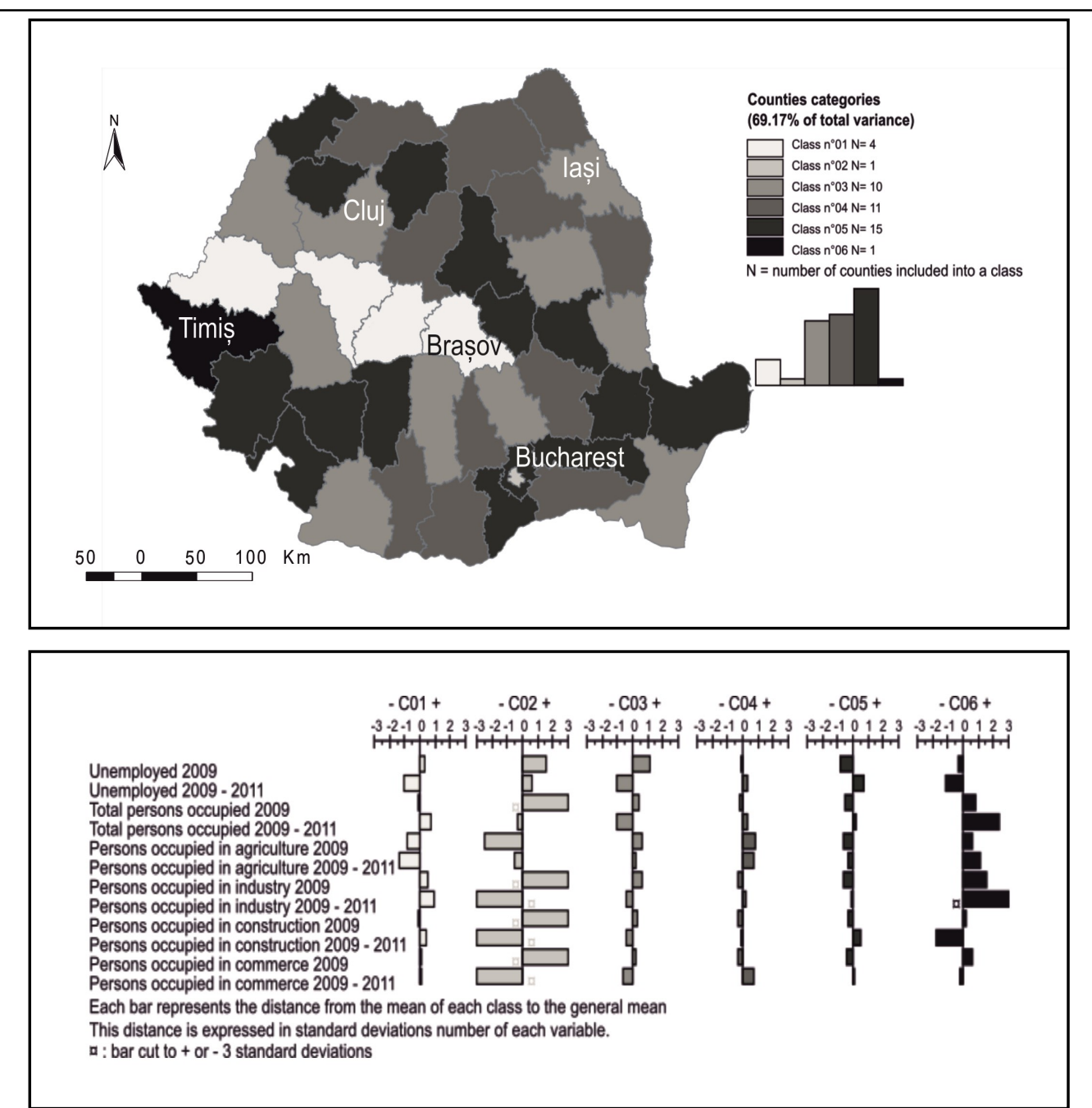

Fig. 1 - Types of counties using the occupied and the unemployed population and the average profile of classes (2009-2011)

Data source: National Institute of Statistics Made with Philcarto (http://philcarto.free.fr)

Class 1. Counties attractive for occupation in industry (conversion from agriculture); Class 2. Counties with strong economic restructuring (convergent to agriculture); Class 3 . Counties repulsive for all economic activities but with the number of occupied people above average at the beginning of the crisis (decreasing number of the occupied and the unemployed population); Class 4. Counties attractive for agriculture and commerce (evolution of the occupied and the unemployed people close to the national average); Class 5. Counties attractive just for constructions and repulsive for other economic activities (growing number of the unemployed and evolving occupation number close to the national average); Class 6 . Counties attractive for agriculture and industry and repulsive for constructions and commerce (decreasing number of the unemployed, and increasing number of occupied people). 

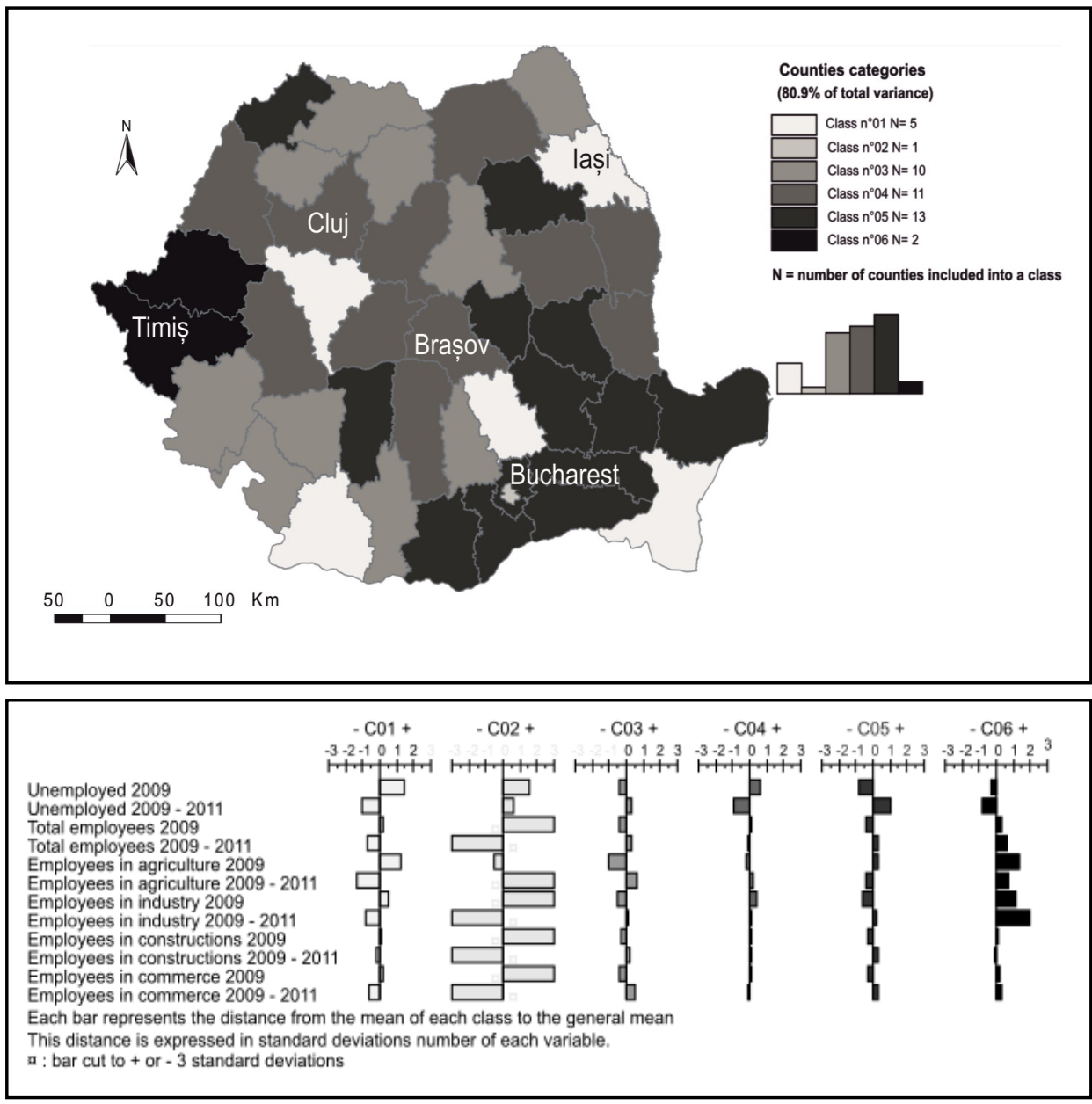

Fig. 2 - Types of counties using employees, unemployed and average profile of classes (2009-2011)

Data source: National Institute of Statistics

Made with Philcarto (http://philcarto.free.fr)

Class 1. Counties repulsive to all economic activities, but the number of employees in agriculture and industry was above the national average at the beginning of the crisis (decreasing number of employees and of the unemployed people); Class 2. Counties with strong economic restructuring (convergent to agriculture); Class 3. Counties more attractive for employment in all economic activities, but the number of employees at the beginning of the crisis was below the national average in all economic activities (evolution of the unemployed and the number of employees close to the national average); Class 4 Counties neutral in terms of attractiveness for all economic activities (decreasing number of the unemployed and the employees evolution close to the national average); Class 5. Counties strongly repulsive to industry (increasing number of the unemployed and employees evolution above the nationa average); Class 6. Counties more attractive for agriculture and industry and neutral attractiveness for constructions and commerce (decreasing number of the unemployed, increasing number of the employees) 
The same process of territorial redistribution can be seen for the number of employees, although county clustering is slightly different (see classes $2,3,5$ ). Noteworthy is the neutral position of class 4 counties, where the evolution of all economic activity is close to the national average (Fig. 2). Overall, the economies most affected by the recent economic crisis belonged to southeastern Romania counties, the number of the unemployed registering a significant increase.

The next step is to analyze the reaction of the population to changes in the economic component, and for this a HAC was run, including data on the number of the unemployed, departures and settling of residence and net migration in 2009 and the evolution of these indicators over 2009-2011.

When the population was laid off it could seek a job in the same county, or change residence to another county, where more jobs were available and employment opportunities were greater. There are strategic economic sectors less vulnerable to crisis, identified by Kerimoglu and Karahasan (2012) as sectors where talent (group of individuals who are highly educated) is present. We see that the southeastern Romanian counties are those that recorded the highest number of resident departures (Fig. 3). This is why, the number of the unemployed increased above the national average. Therefore, changes in the economy led to social changes, the population bearing the effects of the economic crisis. We can say that the economic component plays the role of a dissipative structure in the social-economic system. The information on the extent and spread of the economic crisis in the world crossing that component raises the entropy that was dissipated or exported to the social component (for more details of dissipative structures see Prigogine and Stengers 1984). This meant a self-organization of the economic component, with the cost of increasing entropy in the social component (lanoş 2000). Thus, entropy was transferred from the economic to the social. This can be a way of maintaining order by extending the entropy expression space, as Nemes et al. (2012) suggested. But this process did not stop here; the redundant population's reduced purchasing power affecting domestic consumption. So, the population further influenced the economic component and this circular causality boosted the economic crisis in Romania. Walby (2007) thought on the same line when he concluded that the solution to describe how interlinked systems are is to consider all the other systems as a medium for a system, which implies a mutual impact of systems. We must bring into question the high degree of connection between the economic and the social component. Loosely coupled systems have more time to recover from failure and therefore they are better able to absorb potential shocks, while tightly coupled systems do not allow for delay and therefore increase the risk to amplify the disturbance (Perrow 1999, Duit and Galaz 2008).

The diversity of economic activities in a county is not important for the economic evolution during the crisis. If we look at the data on the evolution of the number of employees at national level in 2009-2011, we understand that an evolution slightly above the national average (approx. -10 000 employees for each county) means a negative trend. The predominance of agriculture (economic sector with lower income) and poor service development in southeastern Romanian counties could lead to seeking jobs outside the county in order to cope with the challenges posed by the changing economy. If the population migration will continue to specific developed regions, this may lead to problems related on population concentration (Afandiyev et al. 2014). The negative feedback loops deepening the system into entropy would have been discontinued, reaching an equilibrium level. This happened in other counties of Romania. When order was gradually restored, we saw the emergence of resilience. 

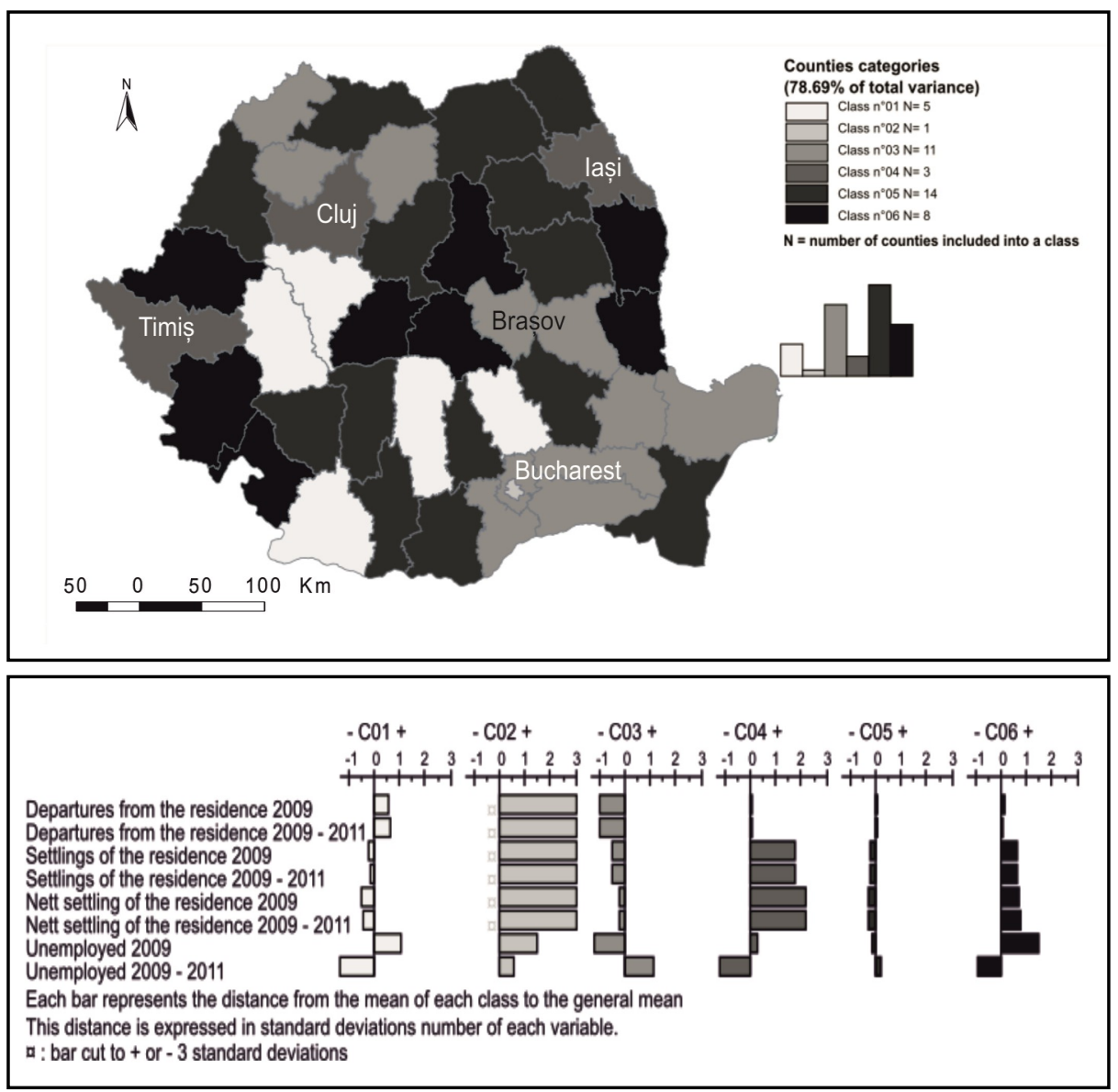

Fig. 3 - Types of counties using indicators of internal migration, number of unemployed and average profile of classes (2009-2011)

Data source: National Institute of Statistics Made with Philcarto (http://philcarto.free.fr)

Class 1. Counties repulsive for living in, but with decreasing number of the unemployed people; Class 2. Counties with strong internal migration movement, but with positive migratory balance and the number of the unemployed slightly increasing; Class 3 . Counties repulsive for living in and increasing unemployment rate; Class 4 . Counties attractive for living in and decreasing unemployment rate but with close to the national average unemployment rate in 2009; Class 5. Counties neutral in terms of attractiveness for living in and unemployment rate evolution close to the national average; Class 6 . Counties attractive for living in and decreasing unemployment rate but with many unemployed people in 2009. 


\section{Conclusions}

The geographical space configures and reconfigures the systems over time. It may bring sufficient evidence to prove that the geographical space is the support and a determinant agent of the systems' development. Social-economic systems at county level are not uniform in composition. However, we cannot say for certain that a county's economic profile has led to diminishing the negative effects of the economic crisis, but this affirmation is certain: the recent economic crisis has led to the spatial redistribution of economic activities. Thus, before the crisis, counties with a higher number of employees in certain sectors than the national average did reduce their activity more sharply, while counties with a lower number of employees suffered slower economic transformation. The population's response to these economic changes was mainly the change of residence. Therefore, the migratory movement was driven by job losses, professional reconversion being an option less considered by the unemployed population.

The importance of this type of analysis is a practical one, enabling decision-makers to act by taking into account the relationships established between the components of the socialeconomic systems. Based on knowledge of causal relations and the interaction between the components, decision-makers can act through the efficient use of resources.

Following the evolution of the economic variables in southeastern Romanian counties over 2009-2011 we see that the effects of several small shocks in different economic activities did not annul each other, but they were rather amplified. Interactions between economic activities being strongly localized mainly in cities, we can better understand people's decision to migrate from one county to another. By changing the place of residence, the macroscopic type of instability that dominates the Romanian economy diminishes, social resilience emerging - a real process of social self-organization.

The most vulnerable regions to economic and financial crises are those where the economic component custody decisions to population, on the labor market. Such situations are common in economies with low competitiveness, where the economic component is subjected to increased competition during the crisis.

\section{Acknowledgments}

This work was supported by the project: POSDRU/159/1.5/S/133391 "Doctoral and postdoctoral programs supporting research", project co-financed through the Sectoral Operational Program for the Development of Human Resources 2007-2013 from the European Social Fund.

\section{References}

AFANDIYEV V., EMINOV Z., NAGIYEV S. (2014), Economic and geographic factors affecting the development of Greater Baku, Journal of Urban and Regional Analysis 6 (2), 203-218.

ADGER W. N. (2000), Social and ecological resilience: are they related? Progress in Human Geography 24 (3), 347-364.

BARTHEL S., PARKER J., FOLKE C., COLDING J. (2014), Urban gardens: pockets of social-ecological memory, in: Tidball K. G., Krasny, M. E. (eds.), Greening in the Red Zone: Disaster, Resilience, and Urgent Biophilia, Springer, Dordrecht, pp. 145-158. 
BRUYNOOGHE M. (1977), Méthodes nouvelles en classification automatique de données taxinomiques nombreuses, Statistique et analyse des données 2 (3), 24-42.

CARPENTER S., WALKER B., ANDERIES J. M., ABEL N. (2001), From metaphor to measurement: Resilience of what to what? Ecosystems 4 (8), 765-781.

COMMON M., PERRINGS C. (1992), Towards an ecological economics of sustainability, Ecological economics 6 (1), 7-34.

DUIT A., GALAZ V. (2008), Governance and complexity - emerging issues for governance theory, Governance 21 (3), 311-335.

FOLKE C., (2006), Resilience: the emergence of a perspective for social-ecological systems analyses, Global Environmental Change 16 (3), 253-267.

GARTSTEIN M., SEAMON E., DISHION T. J. (2014), Geospatial ecology of adolescent problem behavior: contributions of community factors and parental monitoring, Journal of Community Psychology 42 (3), 299-315.

GUAL M. A., NORGAARD R. B. (2010), Bridging ecological and social systems coevolution: A review and proposal, Ecological Economics 69 (4), 707-717.

GUNDERSON L. H. (2002), Adaptive dancing: interactions between social resilience and ecological crises, in: Berkes F., Colding J., Folke C. (eds.), Navigating Social-Ecological Systems. Building Resilience for Complexity and Change, Cambridge University Press, Cambridge, pp. 33-52.

HAYAMI Y., RUTTAN V. W. (1985), Agricultural development: an international perspective, Johns Hopkins University Press, Baltimore.

HOLLING C. S., GUNDERSON L. H. (2002), Resilience and adaptive cycles, in: Gunderson L. H., Holling C. S. (eds.), Panarchy: Understanding Transformation in Human and Natural Systems, Island Press, Washington, DC, pp. 25-62.

HOLLING C. S., SCHINDLER D. W., WALKER B. W., ROUGHGARDEN J. (1995), Biodiversity in the functioning of ecosystems: an ecological synthesis, in: Perrings C., Mäler K.G., Folke C., Holling C. S., Jansson B.-O. (eds.), Biodiversity Loss: Economic and Ecological Issues, Cambridge University Press, Cambridge, pp. 44-83.

IANOŞ I. (2000), Territorial systems. A geographical approach (In Romanian), Technical Publishing House, Bucharest.

KASPERSON R. E., BERBERIAN M. (2011), Integrating science and policy:

Vulnerability and resilience in global environmental change, Routledge, London.

KERIMOGLU E., KARAHASAN B. C. (2012), Geography of talent for understanding regional disparities in Spain, Journal of Urban and Regional Analysis 4 (2), 103-128.

LUTHAR S. S., CUSHING G. (1999), Neighborhood influences and child development: a prospective study of substance abusers' offspring, Development and Psychopathology 11 (4), 763-784.

MACHLIS G. E., FORCE J. E., BALICE R. G. (1990), Timber, minerals, and social change: an exploratory test of two resource-dependent communities, Rural Sociology 55 (3), 411-424.

MOCANU I. (2011), The job exchanges for graduates in Romania - the assessment of the territorial disparities, Journal of Urban and Regional Analysis 3 (2), 159-174.

NEMEŞ V., PETREA R., FILIMON M. (2012), Spatial entropy. A small town perspective. Case study: The town of Marghita, Journal of Urban and Regional Analysis 4 (2), 189-198.

PERMAN R., MA Y., MCGILVRAY J., COMMON M. (2003), Natural resource and environmental economics, Pearson, Harlow.

PERROW C. (1999), Normal accidents: living with high-risk technologies, Princeton University Press, Princeton.

PRIGOGINE I., STENGERS I. (1984), Order out of chaos, Bantam, New York.

RUITENBEEK H. J. (1996), Distribution of ecological entitlements: implications for economic security and population movement, Ecological Economics 17 (1), 49-64.

RUTTAN V. W. (1998), The new growth theory and development economics: a survey, Journal of Development Studies 35 (2), 1-26.

STERN N. (1996), Growth theories, old and new: and the role of agriculture in economic 


\section{Paul-Răzvan ȘERBAN, Cristian TĂLÂNGĂ}

development, FAO Economic and Social Development Paper no. 136, Rome.

WALBY S. (2007), Complexity theory, systems theory, and multiple intersecting social inequalities, Philosophy of the Social Sciences 37 (4), 449-470.

Initial submission: 06.01.2015

Revised submission: 19.04 .2015

Final acceptance: 22.06.2015

Correspondence: Faculty of Geography, University of Bucharest, 1 Nicolae Bălcescu Blv., Bucharest, Romania

E-mail: paulrazvanserban@yahoo.co.uk 